\title{
A wild derived quantitative trait locus on mouse chromosome 2 prevents obesity
}

\author{
Md Bazlur R Mollah, Akira Ishikawa*
}

\begin{abstract}
Background: The genetic architecture of multifactorial traits such as obesity has been poorly understood. Quantitative trait locus (QTL) analysis is widely used to localize loci affecting multifactorial traits on chromosomal regions. However, large confidence intervals and small phenotypic effects of identified QTLs and closely linked loci are impeding the identification of causative genes that underlie the QTLs. Here we developed five subcongenic mouse strains with overlapping and non-overlapping wild-derived genomic regions from an F2 intercross of a previously developed congenic strain, B6.Cg-Pbwg1, and its genetic background strain, C57BL/6J (B6). The subcongenic strains developed were phenotyped on low-fat standard chow and a high-fat diet to fine-map a previously identified obesity QTL. Microarray analysis was performed with Affymetrix GeneChips to search for candidate genes of the QTL.

Results: The obesity QTL was physically mapped to an 8.8-Mb region of mouse chromosome 2. The wild-derived allele significantly decreased white fat pad weight, body weight and serum levels of glucose and triglyceride. It was also resistant to the high-fat diet. Among 29 genes residing within the 8.8-Mb region, Gpd2, Upp2, Acvr1c, March7 and Rbms1 showed great differential expression in livers and/or gonadal fat pads between B6.Cg-Pbwg1 and B6 mice.

Conclusions: The wild-derived QTL allele prevented obesity in both mice fed a low-fat standard diet and mice fed a high-fat diet. This finding will pave the way for identification of causative genes for obesity. A further understanding of this unique QTL effect at genetic and molecular levels may lead to the discovery of new biological and pathologic pathways associated with obesity.
\end{abstract}

\section{Background}

Obesity is a multifactorial disease and is influenced by genetic and environmental components and their interactions. It is an important predisposing factor of serious chronic diseases including type 2 diabetes, hypertension, cardiovascular disease, and some forms of cancer [1]. Despite the identification of several Mendelian genes related to obesity, our understanding of the genetic architecture of the common form of obesity is poor. In recent years, quantitative trait locus (QTL) analysis has become a standard procedure for localizing loci affecting such multifactorial disease traits on chromosomal regions. QTL mapping has revealed many loci related to body weight, growth, obesity and diabetes as reviewed elsewhere [2],

\footnotetext{
* Correspondence: ishikawa@agr.nagoya-u.ac.jp Laboratory of Animal Genetics, Division of Applied Genetics and Physiology, Department of Applied Molecular Bioscience, Graduate School of Bioagricultural Sciences, Nagoya University, Aichi 464-8601, Japan
}

and the number of identified loci is increasing day by day. However, identification of causative genes contributing to variation in traits has proven extremely difficult for three main reasons. First, the confidence intervals of identified QTLs remain wide, usually spanning $10-50 \mathrm{cM}$ and possibly harboring hundreds or thousands of genes [3,4]. Second, each locus often explains only a fraction of the phenotypic variation [5]. Third, a single QTL is likely to be composed of multiple linked QTLs [6,7]. Among the approximately 2000 QTLs reported in rodents, only a few percentages have been cloned, indicating the necessity to confirm the presence of the identified QTL by initial genome-wide analysis and to reduce the confidence interval of the QTL to a level allowing positional cloning by fine mapping [3].

Among several approaches proposed to fine-map a QTL, the use of congenic and subsequently developed subcongenic strains is a traditional but powerful method 
because it allows multiple tests for phenotypic effects on a uniform genetic background except for the QTL region [7-12]. Recently, a new approach with integration of linkage analysis and gene expression profiling has been proposed to search for and identify candidate genes underlying QTLs [11,13-16]. In this study, we thus combined the conventional congenic-subcongenic fine-mapping approach and microarray analysis.

In a previous study, we developed a congenic strain, B6.Cg-Pbwg1, with a 44.1-Mb genomic region derived from the Philippine wild mouse, Mus musculus castaneus, onto the genetic background of a common inbred strain, C57BL/6J (B6), and subsequent QTL analysis in an F2 intercross between B6.Cg-Pbwg1 and B6 revealed several closely linked QTLs affecting body weight gain, lean body weight and obesity within the 44.1-Mb region harboring Pbwg1, a growth QTL on mouse chromosome 2 [6,17]. Four obesity QTLs (Pbwg1.5, Pbwg1.6, Pbwg1.7 and $P b w g 1.8)$ were mapped to a small interval from 39.0 to $75.6 \mathrm{Mb}$ on chromosome 2 [6]. In this study, we developed a series of subcongenic strains derived from B6.Cg-Pbwg1 to fine-map the obesity QTLs and evaluated their effects on standard and high-fat diets. We also searched for candidate genes of the QTLs by microarray analysis.

\section{Results}

\section{Development of subcongenic strains}

F2 mice obtained from an intercross of B6 and B6. Cg-Pbwg1 strains were screened with 25 microsatellite markers (Table 1 ) to detect recombinant mice. The recombinants were mated to fix subcongenic regions. Finally, five subcongenic strains carrying the following wild-derived genomic regions on chromosome 2 were obtained: 30.45-61.54 Mb for B6.Cg-Pbwg1/SR13, 65.1570.48 for B6.Cg-Pbwg1/SR12, 38.09-61.54 for B6.CgPbwg1/SR8, 30.45-52.76 for B6.Cg-Pbwg1/SR3 and 30.45-31.20 for B6.Cg-Pbwg1/SR4 (Figure 1).

\section{Phenotypic characterization of subcongenics}

Since body weight and obesity-related traits are greatly influenced by nutritional environments, these traits were compared among five subcongenic strains and their parental strains, B6.Cg-Pbwg1 and B6, fed the same standard chow. In addition, they were compared among a subset of male mice of three selected subcongenic strains and the parental strains fed a high-fat diet.

We performed re-phenotyping using a new cohort of B6.Cg-Pbwg1 and B6 mice, different from that in our previous study [6]. The original B6.Cg-Pbwg1 congenic strain fed a standard chow diet had a strong phenotypic effect on individual fat pad and total fat pad weights at 13 weeks of age (Table 2), confirming the presence of obesity QTLs identified in our previous study [6].
Table 1 Microsatellite markers used for genotyping and refining subcongenic borders

\begin{tabular}{|c|c|c|}
\hline $\begin{array}{l}\text { Marker } \\
\text { name }\end{array}$ & $\begin{array}{l}\text { Physical map position } \\
\left(\text { bp) }{ }^{\text {a }}\right.\end{array}$ & $\begin{array}{c}\text { Genetic map position } \\
(\mathrm{CM}) \text { b }\end{array}$ \\
\hline D2Mit33 & $30457829-30458008$ & 17.00 \\
\hline D2Mit64 & $31200277-31200449$ & 18.00 \\
\hline D2Mit235 & $32753980-32754099$ & 22.50 \\
\hline D2Mit367 & $33488530-33488680$ & 26.20 \\
\hline D2Mit7 & $38095233-38095379$ & 28.00 \\
\hline D2Mit320 & $39015155-39015274$ & 27.30 \\
\hline D2Mit297 & $42461006-42461146$ & 29.00 \\
\hline D2Mit88 & $45313143-45313324$ & 30.00 \\
\hline D2Mit270 & $52766346-52766428$ & 30.50 \\
\hline D2Mit323 & $55163327-55163451$ & 31.70 \\
\hline D2Mit89 & $56480405-56480598$ & 32.00 \\
\hline D2Mit433 & $57149522-57149694$ & 31.70 \\
\hline D2Mit324 & $58783118-58783242$ & 32.80 \\
\hline D2Mit123 & $59242475-59242615$ & 33.00 \\
\hline D2Mit61 & $60528325-60528469$ & 34.00 \\
\hline D2Mit472 & $61544415-61744509$ & 38.30 \\
\hline D2Mit205 & $65140125-65140208$ & 37.00 \\
\hline D2Mit90 & $65403934-65604017$ & 37.00 \\
\hline D2Mit325 & $67599653-67599827$ & 38.30 \\
\hline D2Mit182 & $68710989-68711138$ & 38.30 \\
\hline D2Mit349 & $69737962-69738092$ & 40.40 \\
\hline D2Mit327 & $69303093-69303218$ & 40.40 \\
\hline D2Mit56 & $70488173-70688291$ & 41.00 \\
\hline D2Mit245 & $72462129-72462229$ & 43.00 \\
\hline D2Mit38 & $74535365-74535555$ & 45.00 \\
\hline
\end{tabular}

aCSC Genome Browser (Mouse, July 2007 assembly). ${ }^{b}$ Mouse Genome Database (September, 2009, release 4.3).

To narrow the genomic region that affects obesity, a phenotypic comparison was made among five subcongenic strains with overlapping and non-overlapping wild-derived genomic regions (Figure 1) fed standard chow. This comparison indicated that at least one locus that affects obesity is located within the region common to B6.Cg-Pbwg1/SR13 and B6.Cg-Pbwg1/SR8 but not to B6.Cg-Pbwg1/SR3. Since the body weight traits of B6. Cg-Pbwg1/SR8 and B6.Cg-Pbwg1/SR12 were significantly different from that of B6 (Table 2), we adjusted obesityrelated traits for lean body weight. A comparison of the adjusted data among the five subcongenic strains supported the results for the above unadjusted data (data not shown).

Similar to the standard chow diet, the B6.Cg-Pbwg1/ SR8 strain fed a high-fat diet showed significantly lower body weight and obesity-related traits (Table 3). When the results obtained from standard chow and high-fat diets were combined and reanalyzed, significant interactions between diet and strain $\left(\mathrm{P}=5.18 \times 10^{-14}-1.18 \times\right.$ $10^{-21}$ ) were found for all fat pad traits (Figure 2). Among the strains examined, B6.Cg-Pbwg1 and B6.Cg-Pbwg1/ 


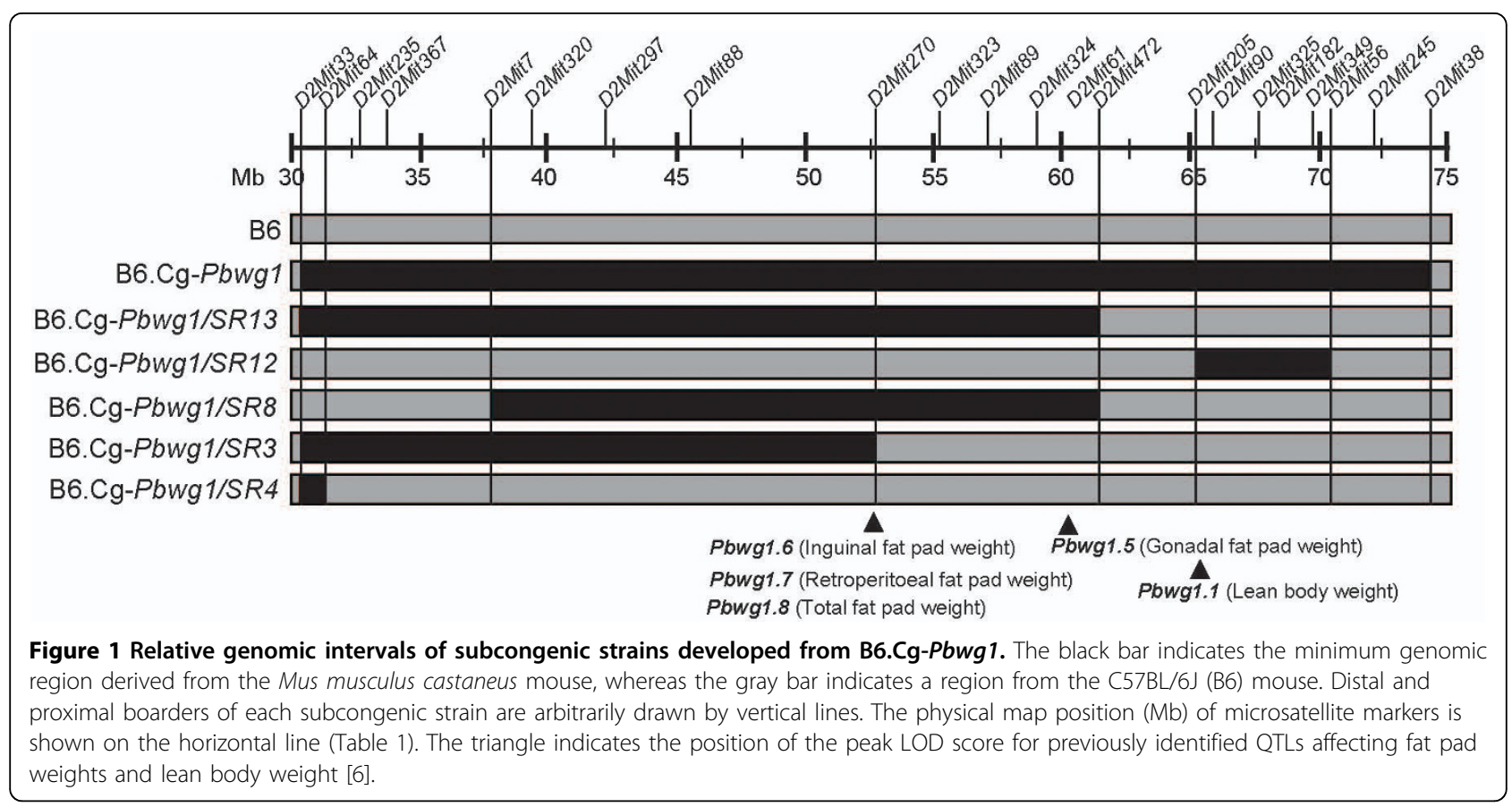

SR8 mice showed strong resistance to diet-induced obesity compared to B6 and two positive control subcongenics, B6.Cg-Pbwg1/SR4 and B6.Cg-Pbwg1/SR12.

From results of the above analyses, the obesity locus was physically defined within an approximately $8.8-\mathrm{Mb}$ region between D2Mit270 and D2Mit472. This region, derived from the wild mouse, was resistant to high-fat diet and contained the positions of peak LOD scores for four previously identified fat pad QTLs, Pbwg1.5 Pbwg1.8 (Figure 1).

\section{Metabolic profiling of selected subcongenics}

Since the B6.Cg-Pbwg1/SR8 subcongenic strain showed significant reductions in body weight and obesity-related traits, the serum levels of glucose, triglyceride, total cholesterol and high density lipoprotein were investigated in this strain in comparison with those in B6 and B6.CgPbwg1/SR4, a positive control, at 13 weeks of age on a standard chow diet. In both sexes, glucose and triglyceride levels were significantly lower in the B6.Cg-Pbwg1/ SR8 strain than in the B6 strain (Figure 3a, b). No significant differences were observed in total cholesterol level between the B6 strain and each of the subcongenic strains (Figure 3c). However, the serum level of high density lipoprotein was lower in males, but not in females, of the B6.Cg-Pbwg1/SR8 strain than in males of the B6 strain (Figure 3d).

\section{Candidate gene analysis}

According to UCSC Genome Browser, the $8.8-\mathrm{Mb}$ region between D2Mit270 and D2Mit472 contained 29 genes. Microarray analysis revealed that four genes in the liver and seven genes in the gonadal fat pad were differentially expressed in B6.Cg-Pbwg1 and B6 strains at a signal $\log$ ratio $\geq 1.0$ (Table 4). Gpd2 was upregulated in both the liver and fat of B6.Cg-Pbwg1 mice, and Acrv1c was upregulated in fat only. On the other hand, Upp 2, March7 and Rbms1 were downregulated in the liver and/or fat of B6.Cg-Pbwg1 mice.

\section{Discussion}

In this study, we revealed that an obesity QTL is located within an approximately $8.8-\mathrm{Mb}$ region between D2Mit270 $(52.76 \mathrm{Mb})$ and D2Mit472 $(61.54 \mathrm{Mb})$ on mouse chromosome 2 and that the QTL effect is resistant to both standard and high-fat diets. Four closely linked obesity QTLs (Pbwg1.5 for gonadal fat pad weight, Pbwg1.6 for inguinal fat pad weight, Pbwg1.7 for retroperitoneal fat pad weight and $P b w g 1.8$ for total fat pad weight) that we found previously reside within this region [6]. Although it was not able to be concluded in the present study whether these four QTLs are the same or different loci, we verified all phenotypic differences defined by our previous study. We are now developing other subcongenics with small regions into which the 8.8-Mb target region will be divided. Phenotypic characterization of those subcongenics will provide a clue for resolving the issue of pleiotropy vs. closely linked loci.

Lipid profiling, especially triglyceride level, is an indirect but well-known measure of obesity, and a strong positive correlation exists between obesity and triglyceride level [18]. On the other hand, a high glucose level in 
Table 2 Obesity traits in five subcongenics and their parental strains on low-fat standard chow diet

\begin{tabular}{|c|c|c|c|c|c|c|c|c|c|}
\hline Sex & Strain & $\mathrm{n}$ & $\begin{array}{l}\text { Body } \\
\text { weight } \\
\text { (g) }\end{array}$ & $\begin{array}{l}\text { Lean body } \\
\text { weight }(g)\end{array}$ & $\begin{array}{l}\text { Inguinal fat pad } \\
\text { weight }(\mathrm{g})\end{array}$ & $\begin{array}{l}\text { Gonadal fat pad } \\
\text { weight }(g)\end{array}$ & $\begin{array}{l}\text { Retroperitoneal fat } \\
\text { pad weight }(\mathrm{g})\end{array}$ & $\begin{array}{l}\text { Total fat pad } \\
\text { weight }(\mathrm{g})\end{array}$ & $\begin{array}{l}\text { Adiposity } \\
\text { index }\end{array}$ \\
\hline \multirow[t]{7}{*}{ Male } & B6 & 45 & $\begin{array}{l}27.28 \pm \\
0.051\end{array}$ & $26.23 \pm 0.048$ & $0.455 \pm 0.005$ & $0.424 \pm 0.003$ & $0.164 \pm 0.003$ & $1.043 \pm 0.009$ & $\begin{array}{l}0.038 \pm \\
0.0003\end{array}$ \\
\hline & $\begin{array}{l}\text { B6.Cg- } \\
\text { Pbwgl }\end{array}$ & 40 & $\begin{array}{l}26.83 \pm \\
0.063\end{array}$ & $26.04 \pm 0.061$ & $0.336 \pm 0.003^{* * *}$ & $0.338 \pm 0.003^{* * *}$ & $0.116 \pm 0.002^{* * *}$ & $\begin{array}{l}0.790 \pm \\
0.004^{* * * *}\end{array}$ & $\begin{array}{l}0.031 \pm \\
0.0007^{* * *}\end{array}$ \\
\hline & $\begin{array}{l}\text { B6.Cg- } \\
\text { Pbwg1/ } \\
\text { SR13 }\end{array}$ & 15 & $\begin{array}{l}27.69 \pm \\
0.057\end{array}$ & $26.90 \pm 0.056$ & $0.345 \pm 0.006^{* *}$ & $0.308 \pm 0.006^{* * *}$ & $0.132 \pm 0.004$ & $\begin{array}{l}0.785 \pm \\
0.014^{* * *}\end{array}$ & $\begin{array}{l}0.035 \pm \\
0.0008^{* * *}\end{array}$ \\
\hline & $\begin{array}{l}\text { B6.Cg- } \\
\text { Pbwg1/ } \\
\text { SR12 }\end{array}$ & 30 & $\begin{array}{l}29.00 \pm \\
0.115^{* *}\end{array}$ & $\begin{array}{l}28.07 \pm \\
0.108^{* *}\end{array}$ & $0.393 \pm 0.007^{*}$ & $0.390 \pm 0.007$ & $0.149 \pm 0.003$ & $0.933 \pm 0.014^{*}$ & $\begin{array}{l}0.028 \pm \\
0.0008^{* * *}\end{array}$ \\
\hline & $\begin{array}{l}\text { B6.Cg- } \\
\text { Pbwg1/SR8 }\end{array}$ & 39 & $\begin{array}{l}26.13 \pm \\
0.055^{*}\end{array}$ & $25.49 \pm 0.054^{*}$ & $0.293 \pm 0.004^{* * *}$ & $0.265 \pm 0.003^{* * *}$ & $0.082 \pm 0.002^{* * *}$ & $\begin{array}{l}0.641 \pm \\
0.007^{* * *}\end{array}$ & $\begin{array}{l}0.030 \pm \\
0.0014^{* * *}\end{array}$ \\
\hline & $\begin{array}{l}\text { B6.Cg- } \\
\text { Pbwg1/SR3 }\end{array}$ & 16 & $\begin{array}{l}27.22 \pm \\
0.039\end{array}$ & $26.19 \pm 0.036$ & $0.439 \pm 0.003$ & $0.453 \pm 0.003$ & $0.176 \pm 0.004$ & $1.029 \pm 0.009$ & $\begin{array}{l}0.031 \pm \\
0.0001\end{array}$ \\
\hline & $\begin{array}{l}\text { B6.Cg- } \\
\text { Pbwg1/SR4 }\end{array}$ & 23 & $\begin{array}{l}28.01 \pm \\
0.172 \\
\end{array}$ & $26.89 \pm 0.157$ & $0.466 \pm 0.011$ & $0.470 \pm 0.006$ & $0.191 \pm 0.007$ & $1.128 \pm 0.022$ & $\begin{array}{l}0.034 \pm \\
0.0011 \\
\end{array}$ \\
\hline \multirow[t]{7}{*}{ Female } & B6 & 39 & $\begin{array}{l}21.96 \pm \\
0.044\end{array}$ & $21.17 \pm 0.043$ & $0.359 \pm 0.002$ & $0.296 \pm 0.002$ & $0.136 \pm 0.001$ & $0.791 \pm 0.003$ & $\begin{array}{l}0.036 \pm \\
0.0002\end{array}$ \\
\hline & $\begin{array}{l}\text { B6.Cg- } \\
\text { Pbwgl }\end{array}$ & 31 & $\begin{array}{l}21.24 \pm \\
0.056^{* *}\end{array}$ & $\begin{array}{l}20.63 \pm \\
0.052^{* *}\end{array}$ & $0.266 \pm 0.002^{* * *}$ & $0.234 \pm 0.002^{* * *}$ & $0.108 \pm 0.001^{* * *}$ & $\begin{array}{l}0.608 \pm \\
0.004^{* * *}\end{array}$ & $\begin{array}{l}0.029 \pm \\
0.0002^{* * *}\end{array}$ \\
\hline & $\begin{array}{l}\text { B6.Cg- } \\
\text { Pbwg1/ } \\
\text { SR13 }\end{array}$ & 14 & $\begin{array}{l}21.03 \pm \\
0.055\end{array}$ & $20.48 \pm 0.053$ & $0.268 \pm 0.001^{* * *}$ & $0.175 \pm 0.003^{* * *}$ & $0.104 \pm 0.001^{*}$ & $\begin{array}{l}0.547 \pm \\
0.005^{* * *}\end{array}$ & $\begin{array}{l}0.026 \pm \\
0.0003^{* * *}\end{array}$ \\
\hline & $\begin{array}{l}\text { B6.Cg- } \\
\text { Pbwg1/ } \\
\text { SR12 }\end{array}$ & 30 & $\begin{array}{l}22.33 \pm \\
0.066\end{array}$ & $21.55 \pm 0.061$ & $0.366 \pm 0.003$ & $0.278 \pm 0.004$ & $0.130 \pm 0.002$ & $0.774 \pm 0.005$ & $\begin{array}{l}0.034 \pm \\
0.0002\end{array}$ \\
\hline & $\begin{array}{l}\text { B6.Cg- } \\
\text { Pbwgl/SR8 }\end{array}$ & 31 & $\begin{array}{l}20.02 \pm \\
0.050^{* * * *}\end{array}$ & $\begin{array}{l}19.59 \pm \\
0.049^{* * * *}\end{array}$ & $0.233 \pm 0.003^{* * *}$ & $0.129 \pm 0.002^{* * *}$ & $0.063 \pm 0.001^{* * *}$ & $\begin{array}{l}0.425 \pm \\
0.004^{* * * *}\end{array}$ & $\begin{array}{l}0.021 \pm \\
0.0002^{* * *}\end{array}$ \\
\hline & $\begin{array}{l}\text { B6.Cg- } \\
\text { Pbwg1/SR3 }\end{array}$ & 14 & $\begin{array}{l}21.81 \pm \\
0.066\end{array}$ & $21.12 \pm 0.067$ & $0.344 \pm 0.002$ & $0.289 \pm 0.002$ & $0.147 \pm 0.001$ & $0.780 \pm 0.005$ & $\begin{array}{l}0.036 \pm \\
0.0003\end{array}$ \\
\hline & $\begin{array}{l}\text { B6.Cg- } \\
\text { Pbwgl/SR4 }\end{array}$ & 27 & $\begin{array}{l}22.14 \pm \\
0.046\end{array}$ & $21.36 \pm 0.041$ & $0.375 \pm 0.005$ & $0.288 \pm 0.005$ & $0.112 \pm 0.002^{*}$ & $0.776 \pm 0.006$ & $\begin{array}{l}0.035 \pm \\
0.0002\end{array}$ \\
\hline
\end{tabular}

Data are least-squared means \pm SE at 13 weeks of age. $n$, number of mice. Sex separated data were analyzed with a linear mixed model (see Materials and Methods) and fat pad weights were not adjusted for lean body weight. Total fat pad weight is the sum of the three fat pad weights. Adiposity index was calculated by dividing total fat pad weight by body weight. The mean with stars $\left({ }^{*}, \mathrm{P}<0.05 ;{ }^{*}, \mathrm{P}<0.01\right.$; $\left.{ }^{* *}, \mathrm{P}<0.001\right)$ within the same sex is significantly different from that of B6 (Dunnett's test).

Table 3 Obesity traits in selected subcongenics and their parental strains on high-fat diet

\begin{tabular}{|c|c|c|c|c|c|c|c|c|}
\hline Strain & $n$ & $\begin{array}{l}\text { Body } \\
\text { weight (g) }\end{array}$ & $\begin{array}{l}\text { Lean body } \\
\text { weight (g) }\end{array}$ & $\begin{array}{l}\text { Inguinal fat pad } \\
\text { weight }(g)\end{array}$ & $\begin{array}{l}\text { Gonadal fat pad } \\
\text { weight }(g)\end{array}$ & $\begin{array}{l}\text { Retroperitoneal fat } \\
\text { pad weight (g) }\end{array}$ & $\begin{array}{l}\text { Total fat pad } \\
\text { weight }(g)\end{array}$ & $\begin{array}{l}\text { Adiposity } \\
\text { index }\end{array}$ \\
\hline $\mathrm{B} 6$ & 15 & $\begin{array}{l}32.318 \pm \\
0.165\end{array}$ & $29.21 \pm 0.127$ & $1.203 \pm 0.024$ & $1.294 \pm 0.039$ & $0.604 \pm 0.021$ & $3.100 \pm 0.083$ & $\begin{array}{l}0.093 \pm \\
0.002\end{array}$ \\
\hline $\begin{array}{l}\text { B6.Cg- } \\
\text { Pbwg1 }\end{array}$ & 12 & $\begin{array}{l}29.752 \pm \\
0.047^{*}\end{array}$ & $28.01 \pm 0.149$ & $0.625 \pm 0.023^{* * *}$ & $0.794 \pm 0.037^{* * *}$ & $0.327 \pm 0.020^{* *}$ & $1.745 \pm 0.081^{* * *}$ & $\begin{array}{l}0.058 \pm \\
0.002^{* * *}\end{array}$ \\
\hline $\begin{array}{l}\text { B6.Cg- } \\
\text { Pbwg1/SR12 }\end{array}$ & 11 & $\begin{array}{l}34.028 \pm \\
0.149\end{array}$ & $30.44 \pm 0.133$ & $1.495 \pm 0.019^{*}$ & $1.418 \pm 0.013^{*}$ & $0.673 \pm 0.011$ & $3.586 \pm 0.044$ & $\begin{array}{l}0.105 \pm \\
0.001\end{array}$ \\
\hline $\begin{array}{l}\text { B6.Cg- } \\
\text { Pbwg1/SR8 }\end{array}$ & 13 & $\begin{array}{l}28.058 \pm \\
0.186^{* *}\end{array}$ & $26.84 \pm 0.147^{*}$ & $0.478 \pm 0.034^{* * *}$ & $0.547 \pm 0.043^{* * *}$ & $0.196 \pm 0.025^{* * *}$ & $1.221 \pm 0.098^{* * *}$ & $\begin{array}{l}0.043 \pm \\
0.003^{* * *}\end{array}$ \\
\hline $\begin{array}{l}\text { B6.Cg- } \\
\text { Pbwg1/SR4 }\end{array}$ & 10 & $\begin{array}{l}31.861 \pm \\
0.234\end{array}$ & $28.89 \pm 0.145$ & $1.134 \pm 0.033$ & $1.274 \pm 0.052$ & $0.563 \pm 0.027$ & $2.970 \pm 0.112$ & $\begin{array}{l}0.092 \pm \\
0.003\end{array}$ \\
\hline
\end{tabular}

Data are least-squared means \pm SE at 13 weeks of age. $n$, number of mice. Data were analyzed with a linear model (see Materials and Methods) and fat pad weights were not adjusted for lean body weight. Total fat pad weight is the sum of the three fat pad weights. Adiposity index was calculated by dividing total fat pad weight by body weight. The mean with stars $\left(*, P<0.05 ;{ }^{* *}, \mathrm{P}<0.01 ;{ }^{* * *}, \mathrm{P}<0.001\right)$ within the same sex is significantly different from that of $\mathrm{B} 6$ (Dunnett's test). 


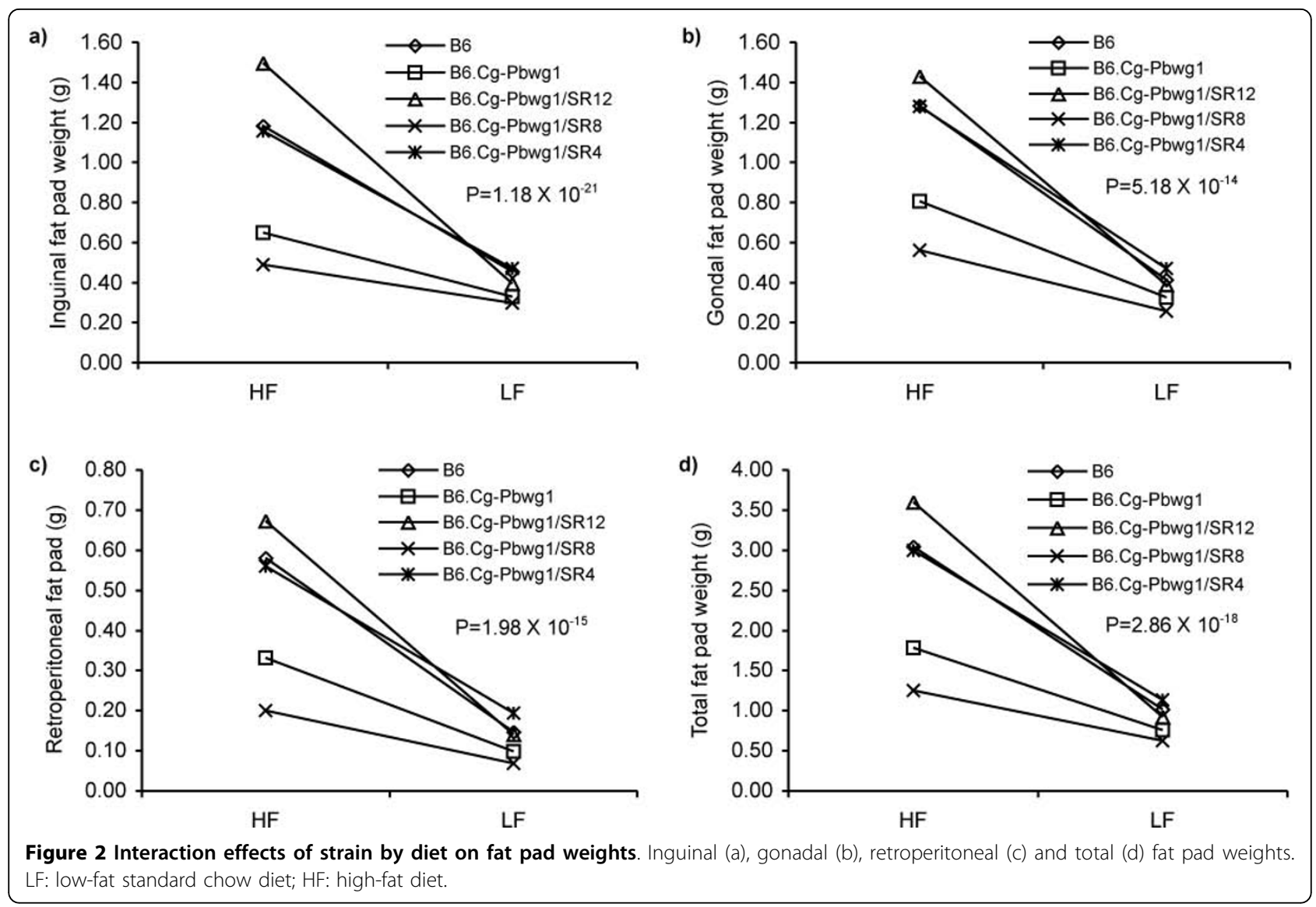

plasma is an indicator of diabetes [19]. Since the genetic background of the B6 strain is susceptible to dietinduced obesity and diabetes, in order to investigate the primary biological function of the present obesity QTL, we measured glucose, triglyceride, total cholesterol and high density lipoprotein levels in serum along with direct measurement of the weight of individual fat depots. Significantly lower glucose and triglyceride levels in B6.Cg-Pbwg1/SR8 subcongenic mice than in the B6 mice suggest that the locus might specifically regulate the energy metabolism and storage or differentiation of adipose tissue. On the other hand, insignificant differences in total cholesterol level between B6 and B6. Cg-Pbwg1/SR8 mice in both sexes suggest that the cholesterol metabolism may be independent of obesity and the gene(s) related to the cholesterol metabolism might reside outside of the present obesity QTL region.

Body weight, obesity and related comorbidities are highly influenced by diet [20], and there is discordance between obesity and related phenotypes [21]. Therefore, we tested the effect of the present obesity QTL on highfat diets. The findings of the present study agreed well with results of studies by Cheverud et al $[20,21]$ showing significant variation between strains in response to high fat feeding.
Many independent studies with different mouse models mapped several QTLs for body weight, growth, adiposity and related traits on mouse chromosome 2 [2]. Among QTLs investigated in other studies, Nidd5, which controls body weight and adiposity, was physically defined to be in a 9.4-Mb interval between D2Mit433 $(57.2 \mathrm{Mb})$ and D2Mit91 (66.6 Mb) by an analysis using congenic mouse strains [8]. This region partially overlaps with our D2Mit270 (52.76 Mb)-D2Mit472 (61.54 $\mathrm{Mb})$ region. In addition, $B w 77$ and Niddm46 both affecting body fat amount in rats [22-24], and BW374_H for abdominal visceral fat in humans [22,25] are mapped to corresponding conserved syntenic intervals for our region. Concordance of QTLs from different genetic studies in mice and other species increases the possibility of having common and strong candidate genes within the chromosomal region of interest [26].

To date, most of the body weight, obesity and diabetes QTL mappings in the mouse have been performed in populations obtained from crosses between common inbred strains that are largely descended from $M . m$. domesticus $[8,20]$. Consequently, the obesity QTLs identified are restricted within a small gene pool of ancestors of the inbred strains. In this study, we used wild $M . m$. castaneus mice captured in the Philippines that have 


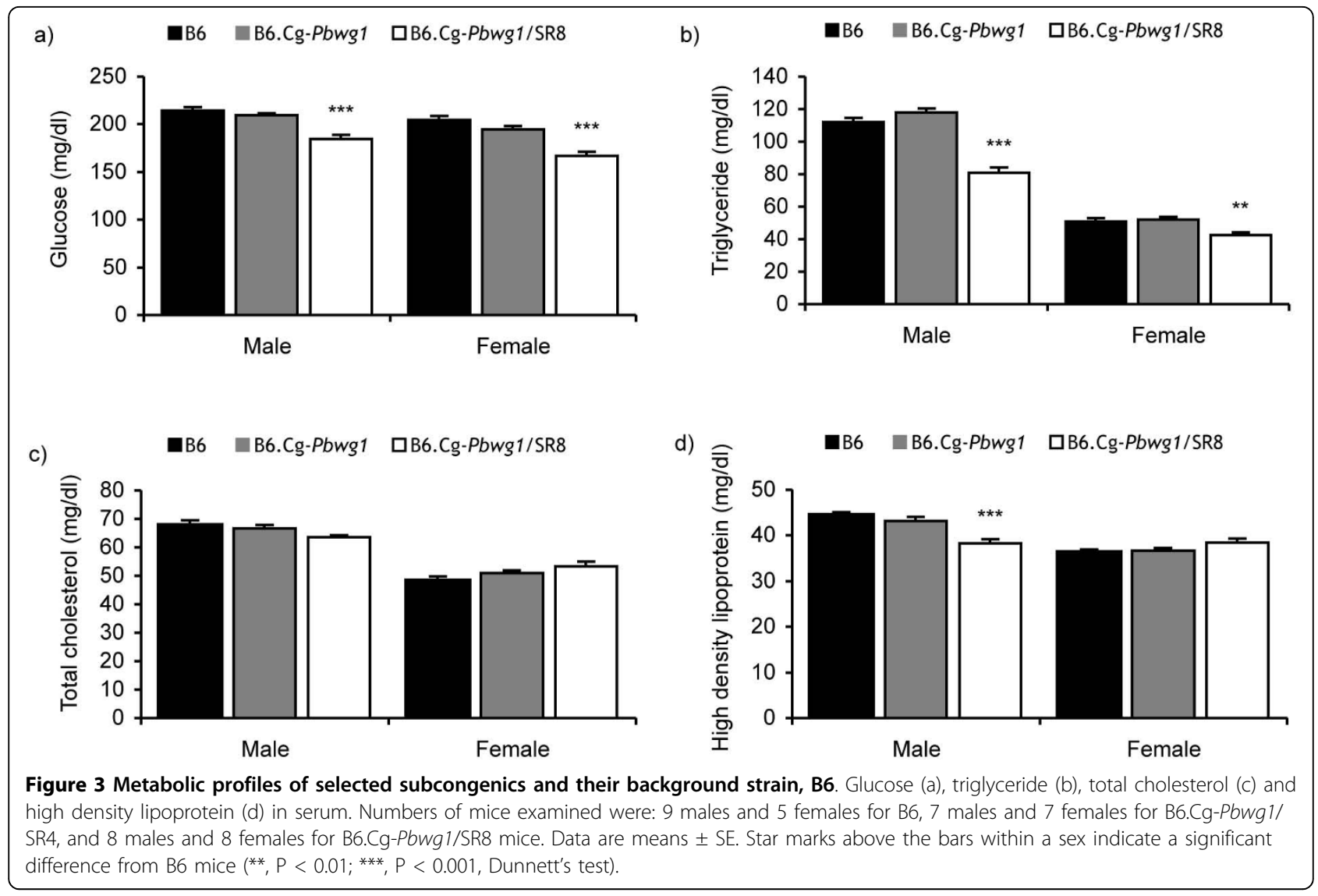

only $60 \%$ of the body weight of the B6 strain [17]. The obesity-resistant QTL allele derived from the wild castaneus mouse must reflect variation in nature, because males obtained from a cross of wild-caught mice were directly used to map QTLs for body weight and growth [17] and thereafter some of the wild-derived QTL alleles discovered have been saved by development of congenic strains $[6,27,28]$. Other studies using wild mice, including M. m. molossinus and M. m. castaneus, have revealed several loci related to growth, obesity, aging, abnormal spermatogenesis, and diabetes [29-33]. Thus, a number of novel QTLs with unique phenotypic effects may remain undiscovered from the gene pools of wild mouse populations.

The use of mice as a model animal for studying genetic influences on obesity is based on the premise that mice and humans share common regulatory systems of body weight and fatness. To date, this has proved to be the case and there are many examples of correspondence in particular genes and phenotypes in

Table 4 Differentially expressed genes in livers and gonadal fat pads of B6.Cg-Pbwg1 and B6 mice

\begin{tabular}{|c|c|c|c|c|c|}
\hline Organ & Probe name & $\begin{array}{l}\text { Gene } \\
\text { symbol }\end{array}$ & Gene name & Alignments (bp) ${ }^{a}$ & $\begin{array}{l}\text { Signal Log } \\
\text { Ratio }^{\text {b }}\end{array}$ \\
\hline \multirow[t]{4}{*}{ Liver } & 1452741_s_at & $G p d 2$ & $\begin{array}{l}\text { Glycerol phosphate dehydrogenase } 2, \\
\text { mitochondrial }\end{array}$ & chr2: 57219081-57223134 & 1.5 \\
\hline & 1424969_s_at & Upp2 & Uridine phosphorylase 2 & chr2: 58607353-58643653 & -1.0 \\
\hline & 1440966_at & March7 & Membrane-associated ring finger $(\mathrm{C} 3 \mathrm{HC} 4) 7$ & chr2: 60084730-60086015 & -2.3 \\
\hline & 1434005_at & Rbms1 & $\begin{array}{l}\text { RNA binding motif single stranded interacting } \\
\text { protein } 1\end{array}$ & chr2: $60588251-60590840$ & -1.0 \\
\hline \multirow[t]{3}{*}{$\begin{array}{l}\text { Gonadal fat } \\
\text { pad }\end{array}$} & 1452741_s_at & $G p d 2$ & $\begin{array}{l}\text { Glycerol phosphate dehydrogenase } 2 \text {, } \\
\text { mitochondrial }\end{array}$ & chr2: 57219081-57223134 & 1.0 \\
\hline & 1443225_at & Acvrlc & Activin receptor type $1 C$ & chr2: 58124237-58124901 & 1.5 \\
\hline & 1440966 at & March7 & Membrane-associated ring finger $(\mathrm{C} 3 \mathrm{HC} 4) 7$ & chr2: $60084730-60086015$ & -1.7 \\
\hline
\end{tabular}

\footnotetext{
${ }^{\mathrm{a}}$ Based on NCBI 37 mouse genome assembly in UCSC Genome Browser. ${ }^{\mathrm{b}}$ A positive value indicates an upregulated gene in B6.Cg-Pbwg1 mice, whereas a
} negative value indicates a downregulated gene in B6.Cg-Pbwg1 mice. 
mice and humans. For example, in mice, mutations in the leptin gene cause early-onset, extreme obesity and the same is true for humans [34,35]. Targeted genetic manipulation in mice has also established vital regulatory roles of molecules in obesity such as the melanocortin 4 receptor (MC4R) [36]. Pro-opimelanocortin, which produces a ligand for MC4R $\alpha$-melanocyte-stimulating hormone, is also involved in human obesity [37].

The region of mouse chromosome 2 reported here has a conserved synteny with the human chromosome 2 region, 2q23.3-q24.2 (154333852 to 162272605 bp). According to the public mouse genome database (NCBI Build 37 on UCSC Genome browser), 29 known protein-coding genes are present within the candidate interval between D2Mit270 and D2Mit472. Since 25 of these genes are also found in the human chromosomal region (2q23.3-q24.2), no homologues of A930012016Rik, AL929070.15, Dapl1 and AL928581.8-1 were found on human chromosomes, suggesting that these four genes on mouse chromosome 2 might be nonfunctional.

Since liver and fat depots are major role players in energy metabolisms and homeostasis, genes for obesity QTLs are expected to be expressed in these tissues. Therefore, to search for specific cis-acting genes that could account for the present results, we performed microarray analysis using the B6.Cg-Pbwg1 congenic strain and its background B6 strain. This analysis can minimize the trans-effects of genes located outside of the congenic region because the congenic and B6 strains have generally the same DNA sequences except for that region. However, trans-acting genes within the region and environmental factors may affect the gene expression levels obtained. Furthermore, we cannot completely rule out the possibility that additional genes on the unwanted donor regions that could not be eliminated by recurrent backcrossing during development of the congenic strain might still affect the gene expression levels. Thus, we are now planning to perform a new gene expression study using an F2 segregating population between a developed subcongenic strain and the B6 strain. The use of the F2 can cancel out the possible effects of trans-acting genes on the unwanted donor regions because their alleles are segregating regardless of diplotype for the subcongenic region of the F2.

Our microarray analysis revealed five genes, Gpd2, Acvr1c, Upp2, March 7 and Rbms1. These genes are highly conserved among different species in terms of gene order, relative transcription direction, sequence similarity, and functional relationships as inferred by gene ontology (Figure 4). Several reports suggest that the sequence of a functionally more important gene has a low rate of evolution such that its orthologs from distantly related species are detectable and alignable [38-40]. Comparative sequence analysis of these genes indicated that they are highly conserved and found from human to zebrafish (Figure 4b). Therefore, we can postulate that these five genes might be involved in obesity. The gene Gpd2 is involved in gluconeogenesis, energy production, and thermogenesis [41,42]. Acvr1c is a type I receptor for the TGFB family of signalling molecules. Upon ligand binding, type I receptors phosphorylate cytoplasmic SMAD transcription factors, which then translocate to the nucleus and interact directly with DNA or in complex with other transcription factors [43]. The functions of Upp2, March7 and Rbms1 are not well understood now.

We also compared the available genomic DNA sequences of the CAST/Ei strain derived from wild $M . m$. castaneus mice trapped in Thailand and the B6 strain using a database [44]. As 286 mutations were discovered in both coding and UTR regions of genes within our target chromosomal region, it was very difficult to make a succinct conclusion about the candidacy of our QTL on the basis of such sequence differences only. Since the DNA sequence of our castaneus mouse is unknown and the origin and breeding strategies are quite different from those of CAST/Ei, we are now planning to sequence genomic DNA and cDNA sequences of the five differentially expressed genes mentioned above to find any mutations, substitutions or deletions in the genes.

\section{Conclusions}

By using a series of subcongenic strains, we physically delineated the region of an obesity QTL previously discovered from an untapped resource of the wild $M . m$. castaneus mouse to an approximately $8.8-\mathrm{Mb}$ interval between D2Mit270 and D2Mit472 on mouse chromosome 2. The wild-derived QTL allele prevents obesity in mice fed both standard and high-fat diets. A further understanding of this unique QTL effect at genetic and molecular levels may lead to the discovery of new biological and pathologic pathways associated with obesity.

\section{Methods}

\section{Construction of subcongenic strains}

B6.Cg-Pbwg1 mice $[6,17]$ were crossed to B6 mice purchased from Clea Japan (Tokyo, Japan), and F1 mice obtained were intercrossed to generate F2 mice. The F2 mice were genotyped for 25 microsatellite markers (Table 1) according to the method described previously [6]. Recombinant individuals were used as founders for development of subcongenic strains.

\section{Diet and husbandry}

All pups were weaned at 3 weeks of age, and then littermates of the same sex were housed in groups of up to three mice per cage. Standard chow (CA-1, Clea Japan, Tokyo, Japan), containing $27.3 \%$ crude protein, $5.1 \%$ crude 


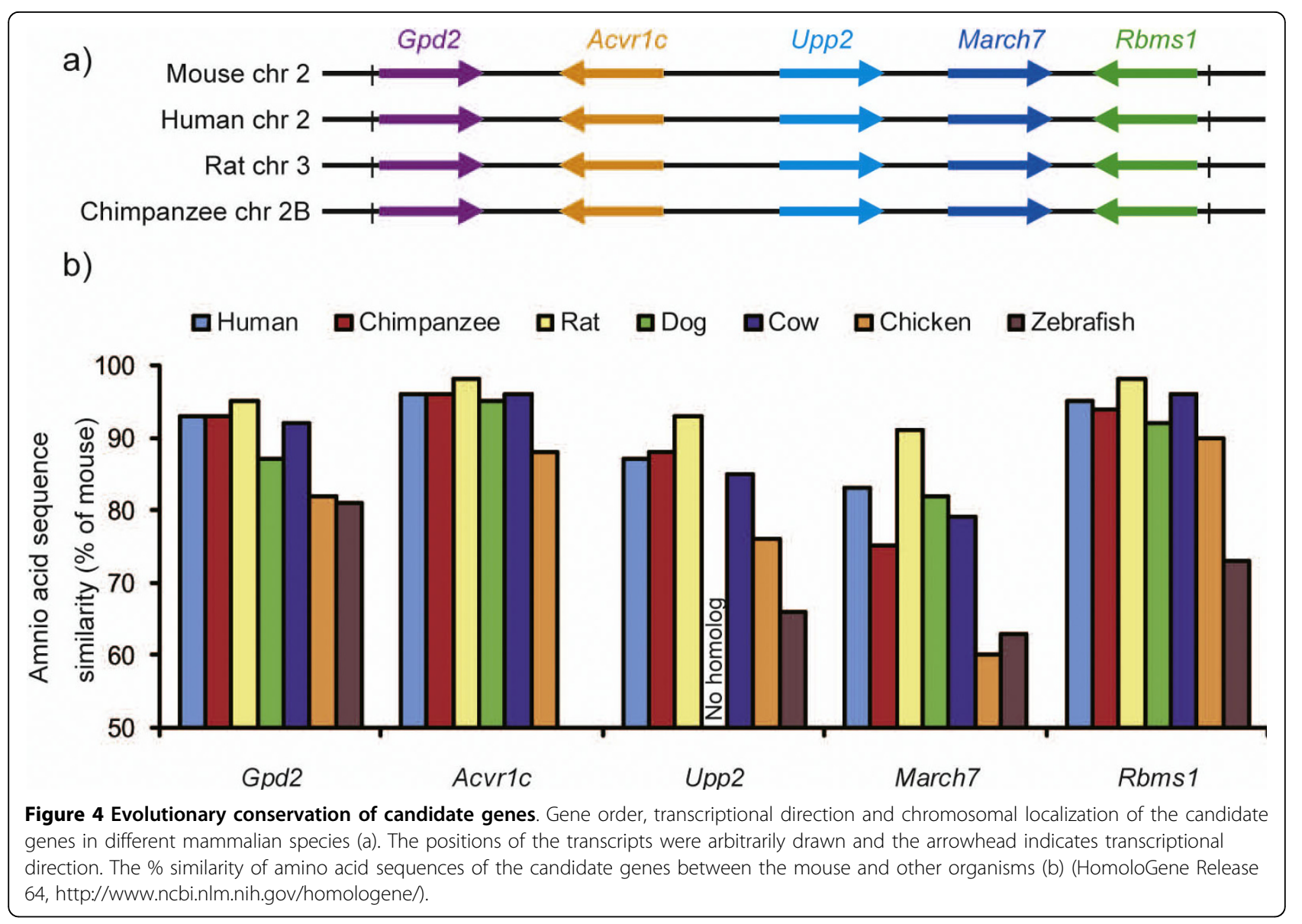

fat, $3.7 \%$ crude fiber, $7.6 \%$ crude ash and $3.45 \mathrm{Kcal} / \mathrm{g}$ energy, and tap water were provided ad libitum. To assess the response to high-fat feeding, a group of male mice from the B6.Cg-Pbwg1 strain and three subcongenic strains, B6. Cg-Pbwg1/SR4, B6.Cg-Pbwg1/SR8 and B6.Cg-Pbwg1/SR12, were fed a purified high-fat diet with $45 \%$ energy from fat ( $24 \%$ crude fat and $4.73 \mathrm{Kcal} / \mathrm{g}$ energy) (Research Diets D12451, Research Diets, New Brunswick, NJ, USA) for 7 weeks from 6 weeks to 13 weeks of age. All mice were reared in an environment with a temperature of $23 \pm 3^{\circ} \mathrm{C}$, $55 \%$ relative humidity, and a light/dark cycle of 12:12. This study was carried out according to the guidelines for the care and use of laboratory animals of the Graduate School of Bioagricultural Sciences, Nagoya University, Japan.

\section{Phenotypic characterization}

Although our previous QTL analysis for obesity-related traits was performed at 10 weeks of age [6], in this study we characterized 273 mice in all subcongenic strains and 182 mice in their parental strains, B6.CgPbwg1 and B6, at 13 weeks of age because phenotypic expression of obesity-related traits was more prominent in older mice. To avoid an arbitrary effect of feed intake on phenotypic values, mice were fasted for four hours and were anesthetized by ether anesthesia before measuring traits as described below. After recording body weight, blood was collected immediately by retro-orbital puncture. Total body length (from the tip of the nose to the end of the tail) and tail length (from the anus to the end of the tail) were measured. Head-body length was obtained by subtracting tail length from total body length. Right and left sides of inguinal, gonadal (epididymal in males and parametrial in females), and retroperitoneal white fat pads were dissected and weighed. The sum of the above three fat pad weights was considered as total fat weight in this study, and the adiposity index was calculated by dividing total fat pad weight by body weight. Lean body weight was computed by subtracting total fat pad weight from body weight. The same person recorded all phenotypic data in order to minimize variation in dissecting techniques. For metabolic profiling of animals, the serum levels of glucose, triglyceride, total cholesterol and high density lipoprotein were determined with the plate reader Sunrise-Basic TECAN (Tecan Japan, Kawasaki, Japan) using glucose CII-test, triglyceride E-test, total cholesterol E-test and HDL-C test Wakos (Wako pure chemical, Osaka, Japan), respectively. 


\section{Microarray analysis}

Livers and gonadal fat pads of three males at 10 weeks of age in each of the B6.Cg-Pbwg1 and B6 strains were collected and immediately immersed in RNAlater reagent (Ambion, Tokyo, Japan). Equal amounts of the three individual samples collected were pooled by tissue and strain. Total RNA extraction with TRIzol reagent (Invitrogen, Tokyo, Japan) and microarray analysis with the Affimetrix GeneChip ${ }^{\circ}$ Mouse Genome 4302.0 array were commissioned to the Bio-medical Department of Kurabo Industries, Ltd. (Osaka, Japan)

\section{Statistical analyses}

Sex-separated phenotypic data from the standard chow diet were analyzed by using a linear mixed model of Lme4 package implemented in R http://www.r-project. org [45]. Effects of strain, parity, litter size and number of animals per cage were treated as fixed effects and the effect of dam was considered as a random effect, and finally the best suitable model was selected on the basis of AIC (Akaike's information criterion) [46]. On the other hand, data from the high-fat diet were analyzed with a linear model that included the effects of strain, parity and litter size as fixed effects. The covariates and their interactions that had significant effects at the nominal 5\% level were included in the final model for comparisons of phenotypic data from the high-fat diet among subcongenics and B6. Metabolic profile data were analyzed by one-way analysis of variance. Differences of B6 vs. congenic or subcongenic strains were determined using Dunnett's post-hoc test.

\section{Acknowledgements \\ MBR Mollah was supported by the Ministry of Education, Culture, Sports, Science and Technology (MEXT) Scholarship of Japanese Government. This work was supported by Grants-in-Aid for Scientific Research (B) from the Japan Society for the Promotion of Science to A Ishikawa. We gratefully acknowledge Dr F Horio for his guidance in serum analyses.}

\section{Authors' contributions}

MBRM carried out the genotyping, phenotyping, statistical analyses and drafting of the manuscript. Al conceived and supervised the study, participated in the design and coordination, created the subcongenic strains and helped to draft the manuscript. All authors read and approved the final manuscript.

Received: 25 March 2010 Accepted: 23 September 2010 Published: 23 September 2010

\section{References}

1. Finer N: Medical consequences of obesity. Medicine 2006, 34:510-514

2. Rankinen T, Zuberi A, Chagnon YC, Weisnagel SJ, Argyropoulos G, Walts B, et al: The human obesity gene map: the 2005 update. Obesity 2006, 14:529-644.

3. Flint J, Valdar W, Shifman S, Mott R: Strategies for mapping and cloning quantitative trait genes in rodents. Nat Rev Genet 2005, 6:271-286.

4. Glazier AM, Nadeau JH, Aitman TJ: Finding genes that underlie complex traits. Science 2002, 298:2345-2349.
5. Cheverud JM, Vaughn TT, Pletscher LS, Peripato AC, Adams ES, Erikson CF: Genetic architecture of adiposity in the cross of LG/J and SM/J inbred mice. Mamm Genome 2001, 12:3-12.

6. Ishikawa A, Kim EH, Bolor H, Mollah MBR, Namikawa T: A growth QTL (Pbwg1) region of mouse chromosome 2 contains closely linked loci affecting growth and body composition. Mamm Genome 2007, 18:229-239.

7. Diament AL, Warden $\mathrm{CH}$ : Multiple linked mouse chromosome 7 loci influence body fat mass. Int J Obes 2004, 28:199-210.

8. Mizutani S, Gomi H, Hirayama I, Tetsuro I: Chromosome 2 locus Nidd5 has a potent effect on adiposity in the TSOD mouse. Mamm Genome 2006, 17:375-384

9. Lyons PA, Hancock WW, Denny P, Lord CJ, Hill NJ, Armitage N, et al: The NOD Idd9 genetic interval influences the pathogenicity of insulitis and contains molecular variants of Cd30, Tnfr2, and Cd137. Immunity 2000, 13:107-115.

10. Pomerleau DP, Bagley RJ, Serreze DV, Mathews CE, Leiter EH: Major histocompatibility complex-linked diabetes susceptibility in NOD/Lt mice: subcongenic analysis localizes a component of Idd 16 at the H2-D end of the diabetogenic H2 (g7) complex. Diabetes 2005, 54:1603-1606.

11. Clee SM, Yandell BS, Schueler KM, Rabaglia ME, Richards OC, Raines SM, et al: Positional cloning of Sorcs1, a type 2 diabetes quantitative trait locus. Nat Genet 2006, 38:688-693.

12. Edderkaoui B, Baylink DJ, Beamer WG, Wergedal JE, Dunn NR, Shultz KL, et al: Multiple genetic loci from CAST/EiJ chromosome 1 affect BMD either positively or negatively in a C57BL/6J background. J Bone Miner Res 2006, 21:97-104.

13. Karp CL, Grupe A, Schadt E, Ewart SL, Keane-Moore M, Cuomo PJ, et al: Identification of complement factor 5 as a susceptibility locus for experimental allergic asthma. Nat Immunol 2000, 1-3:221-226.

14. Mehrabian M, Allayee $\mathrm{H}$, Stockton J, Lum PY, Drake TA, Castellani LW, et al: Integrating genotypic and expression data in a segregating mouse population to identify 5 -lipoxygenase as a susceptibility gene for obesity and bone traits. Nat Genet 2005, 37:1224-1233.

15. Oliver F, Christians JK, Liu X, Rhind S, Verma V, Davison C, et al: Regulatory variation at glypican-3 underlines a major growth QTL in mice. PLoS Biol 2005, 3:e135.

16. Wang $X$, Massimiliano $R$, Kelmenson PM, Eriksson P, Higgins DC, Samnegard A, et al: Positional identification of TNFS4, encoding OX40 ligand, as a gene that influences atherosclerosis susceptibility. Nat Genet 2005, 37:365-372.

17. Ishikawa A, Matsuda Y, Namikawa T: Detection of quantitative trait loci for body weight at 10 weeks from Philippine wild mice. Mamm Genome 2000, 11(10):824-830 [http://www.springerlink.com/content/ $5 \mathrm{c} 31 \mathrm{kk} \times \mathrm{b} 1 \mathrm{~m} 6 \mathrm{ta} 02 \mathrm{n} / \mathrm{s}$

18. Shamai L, Lurix E, Shen M, Novaro GM, Szomstein S, Rosenthal R, Hernandez AV, Asher CR: Association of body mass index and lipid profiles: evaluation of a broad spectrum of body mass index patients including the morbidly obese. Obes Surg 2010.

19. World Health Organization: Definition, diagnosis and classification of diabetes mellitus and its complications: Report of a WHO Consultation. Part 1. Diagnosis and classification of diabetes mellitus. World Health Organization 2006, WHO Press, World Health Organization, 20 Avenue Appia, 1211 Geneva 27, Switzerland.

20. Cheverud JM, Ehrich TH, Hrbek TH, Kenney JP, Pletscher LS, Semenkovich CF: Quantitative trait loci for obesity- and diabetes-related traits and their dietary responses to high-fat feeding in LGXSM recombinant inbred mouse strains. Diabetes 2004, 53:3328-3336.

21. Cheverud JM, Ehrich TH, Kenney JP, Plestscher LS, Semenkovich CF: Genetic evidence for discordance between obesity- and diabetes-related traits in the LGXSM recombinant inbred mouse strains. Diabetes 2004, 53:2700-2708.

22. Stoll M, Cowley AW Jr, Tonellato PJ, Greene AS, Kaldunski ML, Roman RJ, et al: A genomic-systems biology map for cardiovascular function. Science 2001, 294:1723-1726.

23. Seda O, Liska F, Krenova D, Kazdova L, Sedova L, Zima T, et al: Dynamic genetic architecture of metabolic syndrome attributes in the rat. Physio Genomics 2005, 21:243-252.

24. Watanabe TK, Okuno S, Oga K, Mizoguchi-Miyakita A, Tsuji A, Yamasaki Y, et al: Genetic dissection of "OLETF," a rat model for non-insulin- 
dependent diabetes mellitus: quantitative trait locus analysis of (OLETF $\times$ BN) $\times$ OLETF. Genomics 1999, 58:233-239.

25. Rice T, Chagnon YC, Pérusse L, Borecki IB, Ukkola O, Rankinen T, et al: A genomewide linkage scan for abdominal subcutaneous and visceral fat in black and white families: the HERITAGE family study. Diabetes 2002, 51:848-855.

26. Dipetrillo K, Wang X, Stylinanou IM, Paigen B: Bioinformatics toolbox for narrowing rodent quantitative trait loci. Trends Genet 2005, 21:683-692.

27. Ishikawa A, Li C: Development and characterization of a congenic strain carrying Pbwg12, a growth QTL on mouse chromosome 12. Exp Anim 2010, 59:109-113.

28. Ishikawa A, Tanahashi T, Kodama H: A proximal genomic region of mouse chromosome 10 contains quantitative trait loci affecting fatness. Anim SciJ 2010.

29. Anunciado RV, Imamura T, Ohno T, Horio F, Namikawa T: Developing a new model for non-insulin dependent diabetes mellitus (NIDDM) by using the Philippine wild mouse, Mus musculus castaneus. Exp Anim 2000, 49:1-8.

30. Mehrabian M, Wen PZ, Fisler J, Davis RC, Lusis AJ: Genetic loci controlling body fat, lipoprotein metabolism, and insulin levels in a multifactorial mouse model. J Clin Invest 1998, 101:2485-2496.

31. Klebanov S, Astle CM, Roderick TH, Flurkey K, Archer JR, Chen J, Harison DE: Maximum life spans in mice are extended by wild strain alleles. Exp Biol Med 2001, 226:854-859.

32. Jackson AU, Galecki AT, Burke DT, Miller RA: Mouse loci associated with life span exhibit sex-specific and epistatic effects. J Gernotol 2002, 57: B9-B15.

33. Bolor $\mathrm{H}$, Wakasugi $\mathrm{N}$, Zhao WD, Ishikawa A: Detection of quantitative trait loci causing abnormal spermatogenesis and reduced testis weight in the small testis (Smt) mutant mouse. Exp Anim 2006, 55:97-108.

34. Zhang Y, Proenca R, Maffei M, Barone M, Leopold L, Friedman JF: Positional cloning of the mouse obese gene and its human homologue. Nature 1994, 372:425-432.

35. Montague CT, Faroogi IS, Whitehead JP, Soos MA, Rau H, Wareham NJ, et al: Congenital leptin deficiency is associated with severe early-onset obesity in humans. Nature 1997, 387:903-908.

36. Hasuzar D, Lynch CA, Fairchild-Huntress V, Dunmore JH, Fang Q, Berkemeier $L R$, et al: Targeted disruption of the melanocortin-4 receptor results in obesity in mice. Cell 1997, 88:131-141.

37. Krude H, Biebermann H, Luck W, Horn R, Brabant G, Grüters A: Severe early-onset obesity, adrenal insufficiency and red hair pigmentation caused by POMC mutations in humans. Nat Genet 1998, 19:155-157.

38. Karp G: Cell and Molecular Biology Hoboken, New Jersey: John Wiley \& Sons, Inc 2008.

39. Jordan IK, Rogozin IB, Wolf YI, Koonin EV: Essential genes are more evolutionarily conserved than are nonessential genes in bacteria. Genome Res 2002, 12:962-968.

40. Wang Z, Zhang J: Why is the correlation between gene importance and gene evolutionary rate so weak? PLoS Genet 2009, 5:e1000329.

41. Brown LJ, Koza RA, Everett C, Reitman ML, Marshall L, Fahien LA, et al: Normal thyroid thermogenesis but reduced viability and adiposity in mice lacking the mitochondrial glycerol phosphate dehydrogenase. Biol Chem 2002, 277:32892-32898

42. DosSantos RA, Alfadda A, Eto K, Kadowaki T, Silva JE: Evidence for a compensated thermogenic defect in transgenic mice lacking the mitochondrial glycerol-3-phosphate dehydrogenase gene. Endocrinology 2003, 144:5469-79.

43. Bondestam J, Huotari MA, Moren A, Ustinov J, Kaivo-Oja Na, Kallio J, et al: cDNA cloning, expression studies and chromosome mapping of human type I serine/threonine kinase recptor ALK7 (ACVR1C). Cytogent Cell Genet 2001, 95:157-62.

44. Mouse Phenome Database. [http://phenome.jax.org/SNP/].

45. R Development Core Team: R: A Language and Environment for Statistical Computing. 2009 [http://www.r-project.org].

46. Akaike $\mathrm{H}$ : A new look at the statistical model identification. IEEE T Automat Contr 1974, 19:716-723.

doi:10.1186/1471-2156-11-84

Cite this article as: Mollah and Ishikawa: A wild derived quantitative trait locus on mouse chromosome 2 prevents obesity. BMC Genetics 2010 11:84.

\section{Submit your next manuscript to BioMed Central and take full advantage of:}

- Convenient online submission

- Thorough peer review

- No space constraints or color figure charges

- Immediate publication on acceptance

- Inclusion in PubMed, CAS, Scopus and Google Scholar

- Research which is freely available for redistribution 